\title{
Video Games and the 21st Century Design Student: How Might Design Faculty Use Game Play, with Defined Learning Outcomes in a Multiplayer Game, to Improve the Collaboration and Critical Thinking of First-year Design Students?
}

\author{
Guy-Serge Emmanuel \\ University of New Haven, United States
}

\begin{abstract}
The focus of this study is to examine the possibility of applying Digital Game-Based Learning (DGBL) to improve design education at the university level. How might design faculty use game play, with defined learning outcomes in a multiplayer game, to improve the collaboration and critical thinking of first-year design students? Via a systematic literature review and surveys, this research project combines pedagogy and technology to address the current first-year design students' lack of these crucial skills. The literature review will focus on the benefits of DGBL for course design. The surveys, sent to design faculty and students in higher education and design practitioners in the workplace, will focus on building target competencies in first year design courses to bridge the gap between educational practices and employer needs. The findings of this research will be used to develop a $D G B L$ experience for first-year design students which will enhance their collaborative and critical skills.
\end{abstract}

\section{Introduction}

Society's economy pivoted from "commodities and manual labor to an economy based on knowledge and highly qualified human capital" $[1,2]$. Hence, collaboration and critical thinking skills have become invaluable assets in the professional workplace. In order to gain a competitive advantage, employers are looking for designers who can work together with colleagues from various disciplines while having the ability to think critically. For this reason, it is important to prepare students to develop these core competencies as well as learn to engage with their peers from various disciplines. The new generation of learners are growing up spending over $90 \%$ of their time online, either playing games, watching videos, or participating in live video experiences. We cannot minimize this reality and then "expect students to sit in classrooms for traditional methods of lecturebased education" [1].
Digital game-based learning (DGBL) is well suited to tackle the challenges that faculty in education face. DGBL refers to the "usage of the entertaining power of digital games to serve an educational purpose" [3]. As the needs of the workplace have evolved, so have the needs of future learners. If graphic design faculty in higher education fail to realize the needs of the workplace and how to best educate their students, they will be failing both students and their future employers.

Collaboration is the "complex interplay of tasks required by employees to successfully complete a project, as individuals cannot possess all knowledge and abilities" [4]. Employers need personnel who can think critically and that workers require "knowledge that is central to the particular domain" in order to devise methodically "an independent, well-grounded perspective or opinion" [2]. The purpose of this study is to investigate how design faculty can explore the ways in which game play, with defined learning outcomes in a multiplayer game, can improve the collaboration and critical thinking abilities of first-year design students. Studies have shown how "DGBL can positively impact these core competencies in learners" $[5,6]$.

It should be noted that additional research needs to be continued to identify how DGBL experiences should be designed in order to improve graphic design students' abilities in these areas. Having a deeper and fuller understanding of the effects of DGBL specificities could help design faculty in higher education make appropriate curricular choices and take advantage of their benefits to enhance the play-andlearn experience for their students. Using literature reviews and questionnaires, this research project combines pedagogy and technology to develop firstyear design education students' collaborative and critical thinking abilities. The systematic literature 
review will focus on the benefits of DGBL for mastery of these target competencies. The questionnaire to design faculty in higher education will survey the present educational landscape, while the questionnaire to employers will focus on surveying workplace needs. The findings of literature reviews and the questionnaires will be used to develop a DGBL experience for first-year design students. In a classroom environment, the DGBL experience will be evaluated against "traditional" style learning. The findings of this evaluation will then be used to re-evaluate the research.

\section{Literature Review}

Today, the world faces a plethora of new threats such as global warming, public health, and uneven social economic development. Designers' roles are not only crucial in designing but "managing beyond the design studio- even deciding upon the activities that need to be done across departments within a business" [7]. The main trouble with design schools seems to be that they teach too much design and not enough about the ecological, social, economic, and political contexts in which design takes place. It is impossible to teach anything in a vacuum, least of all in a field as deeply involved with basic human needs as graphic design. This literature review examines the benefits of DGBL for developing graphic design students' collaborative and critical capabilities, as well preparing future designers for the $21^{\text {st }}$ century workplace, by resolving what can be described as the "dichotomy between the real world and the world of the school" [8].

Clients need designers who possess a wide range of skills. The days of possessing a strong portfolio of work are over. Today, "clients are exposed to design everyday through a variety of spatial and visual experiences including social media, print sources, products, as well as via human interaction" [9]. Finally, clients are truly understanding the impact of design. They realize that design touches "everything now more than ever before, and they want their design partner to be able to create all these broad touchpoints for them" [9]. Thus, it is important for design students to be ready to demonstrate these abilities in the $21^{\text {st }}$ century workplace. The typical curriculum for design education usually focuses on three disciplines, namely, art, science, and technology, "enclosed within a general purpose for design" [10], as these are crucial for graduate workplace preparation. As the opportunities and demands of practice rapidly evolve, design professionals are embracing interdisciplinary design, which refers to the "cooperative working processes of design professionals (and sometimes non-design professionals) to solve problems together" [9].

There is empirical evidence that games can be an effective tool to enhance learning and understanding of complex subject matter [11]. Bowman et al. explain that it is time that design educators realize that "DGBL experiences can also improve students' academic achievement and improve $21^{\text {st }}$ century competencies such as creativity, problem-solving, collaboration, and critical thinking", all skills needed for a designer [12]. Since the Bauhaus days, "part of the atelier teaching of the design field" is that design students learn by doing. "This is especially valuable to design students as it allows them to learn and implement their design knowledge without real-life repercussions" [13]. Working as part of a team is not only a sign of a good designer but also a good employee, given "the importance of intragroup cooperation and sense of belonging as key factors of motivation and engagement in multi-player GBL" [13]. When selecting a DGBL experience where collaboration is a learning outcome, educators should contemplate using "Serious Games to foster collaborative learning" [13]. M multiplayer games are designed with learning methodologies which emphasize that "generative discussion as well as seeking and giving help in the gamified learning context enhances learners' affective, cognitive, behavioural and sociocultural engagement" [14] as "interaction between learners during the learning process has been found to increase retention of knowledge" [15].

In 2009, Partnership for $21^{\text {st }}$ Century Skills, a national organization, reported that employers' "demands for workplace skills and the ability to develop professional competence highlighted the importance of creative thinking, critical thinking, and problemsolving, as well as communication, information and communication technology (ICT), and cooperative abilities" for college students [16]. There is empirical evidence that "student learning benefits from a studentcentered approach to problem-based learning which adopts authentic employment-based learning and involves teamwork" [16]. Nowadays, employers want workers who can think critically and solve problems. They encourage curricular revisions as "classes which rely upon lower-level thinking and fail to provide opportunities for critical thinking will jeopardize the employability of graduates" [16].

\section{Methodology}

As an interpretivist/constructivist, the researcher understands individuals are self-aware and complex and 
acknowledge that different people experience and interpret the same reality differently. Therefore, this study will be shaped using a mixed-method inquiry interpretive framework, rooted in a constructivist epistemological perspective, which will provide a theoretical construct and analytical focus for the research process. The purpose of this study is to explore how DGBL can be used to improve the teaching of 2D and 3D geometries in first-year design courses. Mixing both qualitative and quantitative methodologies allows additional insight through deduction by testing objective theories as well as developing a deeper understanding of the meaning of the results gathered.

Participants will be recruited from the rank of firstyear Art and Design students at the University of New Haven studying Art, Digital Art and Design, Graphic Design, or Interior Design. A maximum of five participants will be selected per semester, over the course of two years, for a total of roughly 40 students. Faculty teaching the foundational 2D and 3D design offerings will also be recruited to participate as their impact on the research is also valuable. The first course that design students often take, regardless of the higher education institution they attend, is 2D Design. This course covers 2D geometries and is usually offered in the Fall semester; its counterpart, 3D Design, covers 3D geometries and is offered in the Spring semester. Student participants who are early adopters of technology, in particular those familiar with virtual reality, will be recruited with the understanding that they will show greater interest in their participation. For faculty, the allure will be a possible co-pi role on a grant.

Grounded theory, the method on which this study will be built, is a theoretical framework used to develop a new theory, wherein the new theory emerges from an established theory. It is important to "situate grounded theory methodology with an awareness of the interrelationships among conditions, interactions between people, and the structures that illuminate how a process occurs" [17]. In this study, a dataset will be used to create an emerging theory that predicts gameplay, with defined learning outcomes, will positively influence first-year design students' critical thinking and collaboration competencies.

As this is a mixed method study, both qualitative and quantitative methodologies will be employed in order to collect the data. To that end, there will be a series of two 45-minute in-depth interviews of participants, both students and instructors, to gather qualitative data through the creation of a participatory environment the goal of which being to "co-construct the meaning in interviews and in turn generate the grounding of the theoretical rendering" [18]. The interviews will be recorded and then transcribed verbatim. In addition, a review of the students' course assignments might inform the research on a collaborative participant problem solving process and guide the interview questions as well as provide more data to analyze. The completion of the course assignments and the design process used by the participants may vary, thus affecting the line of questioning a participant might receive. While interviewing as many participants as possible would be optimal, it is not feasible. Therefore, surveys will be used in order to gather a wide range of quantitative data for study, from a larger pool of participants. Only design faculty belonging to the $90+$ member institutions of the National Portfolio Day Association will be selected. In order to maintain consistency, design educators and practitioners will also have to be members of their respective professional association such as: the Interior Design Educators Council and the American Society of Interior Designers for interior design faculty and professionals, Industrial Designers Society of America for industrial design, or the American Institute of Graphic Arts for graphic design. Recruitment of the design faculty and professionals will be done via email with an invitation to participate in the study. Additionally, faculty selection will focus on individuals who teach or have taught 2D and 3D design. As for design practitioners, a minimum of 10 years of experience practicing in interior design, industrial design, or graphic design will be considered a sufficient level of experience.

The first web-based survey will focus on foundational design courses and therefore will be distributed to design faculty who teach $2 \mathrm{D}$ and $3 \mathrm{D}$ geometries. The second will be distributed more widely, to all Art and Design students, from first to senior year. These two selection criteria should encompass the majority of students enrolled in art and design whether they are studying graphic, interior, or industrial design. The third and final survey, regarding collaboration and critical thinking skills in the $21^{\text {st }}$ century workplace and on the gap between design education and design practice, will be sent to design studios of varying sizes from the East Coast of the United States and practitioners who meet the minimum experiential qualifications. The goal will be to include architectural, graphic, industrial, and product design studios and practitioners. Respondents will need between 15 to 30 minutes to complete the survey.

Alongside a systematic literature review on DGBL and Design education, the survey to design faculty and students will explore how DGBL might improve these 
target abilities as well as the teaching of 2D and 3D geometries. The surveys to design practitioners will focus on these crucial skills and their necessity to succeed in the $21^{\text {st }}$ century workplace.

Finally, a case study where a role playing, first player, and multiplayer game will be designed, reviewed, and implemented based on the findings from the literature review and data. See Figure 1 below for a visual representation of the implementation of the DGBL aspect of this project.

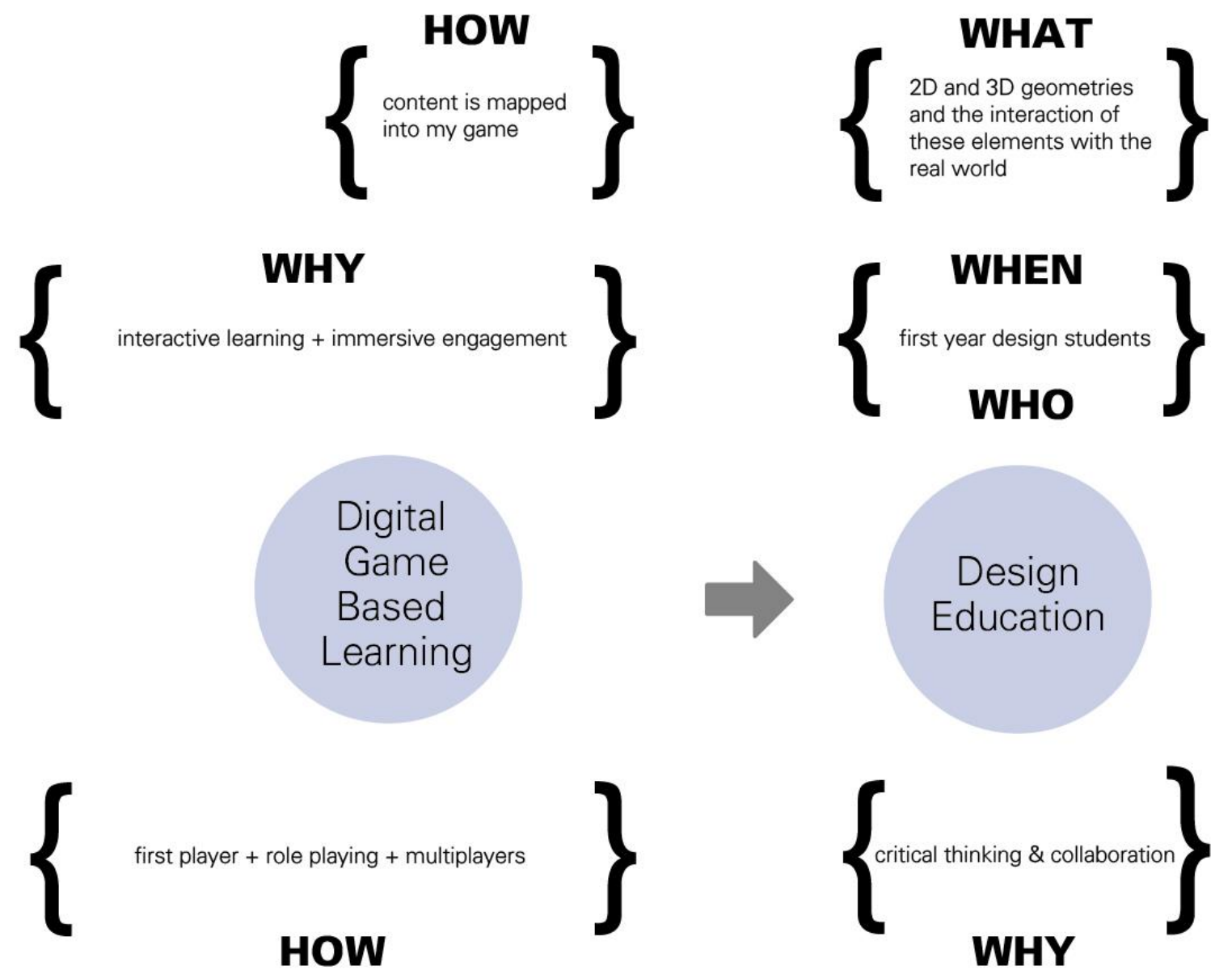

Figure 1. Conceptual Diagram

The literature review for DGBL will include articles by Jean Paul Gee, considered by some the grandfather of DGBL, and other theorists such as Marc Prensky. The DGBL literature focus will be on games which use first player, role playing, and multi-player game mechanics, with an emphasis on their role in developing collaboration and critical thinking competencies. While the research field for DGBL is fairly new, it has slowly been growing as design educators integrate DGBL into their course design with the goal of improving the technical drawing abilities of their students and the teaching of Advertising Design. The literature review for 
design and design education will include articles by Don Norman in order to get a better understanding of how DGBL might be utilized to fill the gap between design education and design practice in the $21^{\text {st }}$ century workplace. A preliminary search will focus on articles containing keywords such as "interdisciplinary" and "technology", as design is becoming increasingly interdisciplinary and evolving alongside technology.

Using Grounded Theory, I will focus on reviewing articles about DGBL and design education. This process will require a critical appraisal identifying the "why", "what", "when", and "how" of the literature review. Collecting qualitative data from various sources will allow verification of the validity of using DGBL in the teaching of $2 \mathrm{D}$ and $3 \mathrm{D}$ geometries to first-year design students, specifically with the goal of improving their collaborative and critical thinking skills. Use of qualitative research techniques is necessary to capture accurate and in-depth insights describing individual experiences and beliefs, which will necessitate appropriate open-ended items in the surveys. I will scan and interpret primary data for most commonly used, as well as emotionally oriented, words and phrases used by respondents. In this study, a dataset will be used to test the theory that predicts content mapped into a game will positively influence the target outcomes for first-year students in design and create a DGBL experience. It can be stated that "while doing grounded theory, concepts come from the data; they are not preconceived or imposed on data. This is particularly important when data, methods and techniques are mixed - the quantitative and qualitative components are not used for verification or testing, but for further elaboration of the theory" [19]. Furthermore, the "purpose is theory building: Discovering patterns (induction), testing theories (deduction) and relying on the best explanation to understand obtained results (abduction) are components of the scientific process, leading to modifiable, self-correcting theories" [19].

The collected data will be broken into themes and repeating words/phrases from the interview process and the surveys will be placed together using axial coding, which makes connections between categories that reveal themes, new categories, or new subcategories. The goal is to categorize and relate pieces of data to each other. When the categorization is complete, themes from the data will emerge. Key words from the interviews and surveys will be analyzed for evidence of patterns from which a new theory can be postulated or grounded from an existing theory. This theory will then be applied to the creation of the DGBL experience used to teach 2D and 3D geometries to first-year design students.

\section{Conclusion}

The significance of this research is based on the fact that we must better prepare design students for the $21^{\text {st }}$ century workplace. As the new generation of learners grows up spending the bulk of their time online posting and watching videos, communicating with others, and playing video games, educators must adapt in order to educate their students effectively. At the same time, the workplace of yesteryear is no more. A designer must be able to work with others from different disciplines and have the ability to think critically in the work environment. The findings of this research will be used to create a game offering a design focused DGBL experience. Future research would involve comparing the effectiveness of the DGBL experience to that of traditional methods of teaching of 2D/3D geometries with the goal of evaluating the efficacy of DGBL in enhancing these competencies in the design classroom.

Due to limited DGBL equipment for the participants, the number of student participants will be restricted and this will impact the scope of data available for analysis. Further research, with greater access to the relevant equipment, would mitigate this issue and provide more significant data. Additionally, self-report will be dependent on participant integrity during the interview process. Trustworthiness of data may also be impacted by the seriousness with which respondents engage with survey questions. Finally, due to the nascent nature of literature on DGBL, in particular with regards to its place in design education, these preliminary investigations are an attempt to establish a firmer foundation for the field of study. As DGBL continues to be employed in the classroom, the literature will become correspondingly more robust through the addition of more research and case studies. In particular, future ludology research should focus on some of the other 21" Century skills needed by the students, such as creativity, communication, innovation, and leadership [20] to name a few.

\section{References}

[1] $\mathrm{Hu} \mathrm{Au,} \mathrm{E.,} \mathrm{and} \mathrm{Lee,} \mathrm{J.} \mathrm{J.} \mathrm{"Virtual} \mathrm{reality} \mathrm{in} \mathrm{education:} \mathrm{a}$ tool for learning in the experience age." International Journal of Innovation in Education, 4(4), 2017, pp. 215-226, DOI: 10.1504/IJIIE.2017.10012691. (Access Date: 3 September 2020).

[2] Van Laar, E., van Deursen, A. J. A. M., van Dijk, J. A. G. M., and de Haan, J. "Determinants of 21 st-Century Skills and 21st-Century Digital Skills for Workers: A Systematic Literature Review." SAGE Open, 10(1). January-March 2020, pp. 1-14 DOI: 10.1177/2158244019900176. (Access Date: 1 November 2020). 
[3] Prensky, M. "Chapter 2: The Games Generations: How Learners Have Changed." Digital Game-Based Learning, McGraw-Hill. 2001.

[4] Wang, Q. "Using online shared workspaces to support group collaborative learning." Computers and Education, 55(3), 2010, 1270-1276. DOI: 10.1016/j.compedu.2010.0

5.023. (Access Date: 22 September 2020).

[5] All, A., Nuñez Castellar, E. P., and Van Looy, J., "Assessing the effectiveness of digital game-based learning: Best practices." Computers and Education, 2016, pp. 90-103. http://dx.doi.org/10.1016/j.compedu.2015.10.007. (Access Date: 2 November 2020).

[6] Romero, M., Usart, M., Ott, M., Earp, J., De Freitas, S., and Arnab, S. "Learning through playing for or against each other? Promoting collaborative learning in digital game-based learning Connectivism." International Journal of Higher Education, 3(3), 2012, pp. 81-91. DOI: 10.5430/ijhe.v3n3p81. (Access Date: 23 September 2020).

[7] Meyer, M. W., and Norman, D. Changing Design Education for the 21st Century. She Ji, 6(1), 2020, 13-49. https://doi.org/10.1016/j.sheji.2019.12.002 (Access Date: 13 November 2020).

[8] Papanek, V. J. Design for the real world: Human ecology and social change. Chicago: Academy Chicago Publishers. 2012.

[9] Hill, D., and Design, T. "Interdisciplinary Design Education is Critical to Solving Complex and Global Problems." 2018, 1-5. https://arcd.ku.edu/sites/arcd.ku.edu/ files/files/2019-01 25_KU\%20ArcD\%20Future\%20of \%20the \%20Professions\%20White\%20Paper.pdf. (Access Date: 14 November 2020).

[10] Findeli, A. "Rethinking Design Education for the 21st Century: Theoretical, Methodological, and Ethical Discussion." Design, 17(1), 2001, 5-17. DOI: 10.1162/07479360152103796. (Access Date: 10 November 2020).

[11] Lee, Y. "Considerations for The Design Game-Based Learning." Educational Technology, 50(2), 2018, 25-28. https://www.jstor.org/stable/44429774. (Access Date 26 September 2020).

[12] Benhamnia, N. et al. "The effective components of creativity in digital game-based learning among young children: A case study." Children and Youth Services Review, 116, 2002, 1-13. DOI: 10.1016/j.childyouth.2020.105227.

(Access Date: 2 December 2020).

[13] Weaver, Nicholas. "The Atelier Principle in Teaching." Symposium on New Directions of Architectural Education the necessity of a cultural paradigm responsive to the majority. GREHA. Delhi, India: Greha, 1999. https:// architexturez.net/doc/az-cf-21655. (Access Date: 5 November 2020).
[14] Plass, J. L., Homer, B. D., \& Kinzer, C. K. (2015). Foundations of Game-Based Learning. Educational Psychologist, 50(4), 258-283. https:// doi.org/10.1080/00461520.2015.1122533. (Access Date: 19 August 2020)

[15] Leonard, S., and Oberprieler, K. "Gamifying design education." Conference Proceedings of the Academy for Design Innovation Management, 2018, pp. $20 \mathrm{https}$ ://w ww.researchgate.net/publication/316172890. (Access Date: 15 November 2020).

[16] Yang, Y. T. C. (2015). Virtual CEOs: A blended approach to digital gaming for enhancing higher order thinking and academic achievement among vocational high school students. Computers and Education, 81, 2015, 281295. DOI: 10.1016/j.compedu.2014.10.004 (Access Date: 29 November 2020).

[17] Khan, S. N. (2014). Qualitative Research Method: Grounded Theory. International Journal of Business and Management, 9(11), 224-233. https://doi.org/10.5539/ ijbm.v9n11p224. (Access Date: 13 June 2021).

[18] LePeau, L. "A grounded theory of academic affairs and student affairs partnerships for diversity and inclusion aims." Review of Higher Education, 39(1), 2015, 97-122. https:// doi.org/10.1353/rhe.2015.0044. (Access Date: 27 June 2021).

[19] Walsh, I. "Using quantitative data in mixed-design grounded theory studies: An enhanced path to formal grounded theory in information systems.” European Journal of Information Systems, 24(5), 2015, 531-557. https:// doi.org/10 .1057/ejis.2014.23 (Access Date: 15 July 2021).

[20] Kivunja, C. "Do You Want Your Students to Be JobReady with 21st Century Skills? Change Pedagogies: A Pedagogical Paradigm Shift from Vygotskyian Social Constructivism to Critical Thinking, Problem Solving and Siemens' Digital Connectivism." International Journal of Higher Education, 3(3), 2014, 81-91. https:// doi.org/10.5430/ijhe.v3n3p81. (Access Date 1 November 2020). 